\title{
GÉNERO
}

\section{Contexto escolar e imagen de género. Percepción de mujeres que ocupan cargos intermedios en una institución de educación superior}

\author{
Karen Natali Backes Dos Santos ${ }^{1}$, María Victoria Zavala Saucedo
}

\section{Resumen}

Introducción: La construcción de la imagen de género es un proceso complejo de aculturación y endoculturación aprendidos, a través del cual el ser humano desarrolla, ejercita, mejora o empeora las enseñanzas de género que han recibido de múltiples mentores.

Este proceso inicia desde el momento en que se sabe el sexo del bebé; posteriormente se identifican dos contextos fundamentales para la construcción y reafirmación de la identidad de género: el familiar y el escolar. La familia, como primer contacto social del niño recién nacido y desde temprano, la que estimula el sistema de diferenciación de valores y normas entre ambos sexos; la escuela, espacio en el que se reafirma ese sistema asentando así, tanto la identidad como el rol de género. En este sentido, la escuela (debido a que la edad de participación es un terreno fértil para la asimilación de conductas y roles sociales) a más de sus funciones formativas, cumple un papel elemental en la vida de una persona, es un espacio que permite la socialización con los pares, por lo tanto, es uno de los principales formadores desde la infancia; lo que permite adquirir un manejo para el desarrollo social propio de cada persona. Así también, es un espacio de incorporación de mecanismos represivos y con censuras específicas, como horarios fijos, programas en función de la edad y desarrollo, el uso de uniformes, la pasividad y la separación por sexo.

Objetivo: Explorar las percepciones de imagen de género en el contexto escolar de las mujeres que ocupan cargos intermedios en una Institución de Educación Superior.

Material y Método: Esta investigación fue de tipo aplicada de diseño no experimental, transversal, alcance descriptivo y con enfoque cuantitativo. A través de la técnica de muestreo probabilístico por conglomerados se definió una muestra integrada por 128 funcionarias. La recolección de datos se realizó mediante una encuesta tipo cuestionario, la cual contaba con 17 ítems (escala

\footnotetext{
1. Escuela de Posgrado de la Universidad Nacional del Este.

Este trabajo forma parte de una tesis para acceder al título de Magíster en Investigación Científica; este resultado aún no ha sido publicado, tampoco presentado en otro evento científico.

E-mail: karencitanbd@gmail.com

DOI: 10.26885/rcei.foro.2018.92
} 


\section{Contexto escolar e imagen de género. Backes \& Zavala}

de Likert), de los cuales 10 marcaban actitudes positivas y 7 actitudes negativas. Resultados: Existe un alto porcentaje de experiencias vividas por las mujeres en el contexto escolar que se vinculan a la imagen estereotipada de género que hacen referencia a la organización, al esfuerzo intelectual y/o creativo por las habilidades para relacionarse y servir a los demás, dando continuidad a las tareas aprendidas y observadas en el contexto familiar

Conclusiones: En la escuela las actividades reproducen esquemas aprendidos en el contexto familiar; de tal manera que las mujeres reafirman su identidad femenina de género en base a estereotipos que indican que los roles de las mujeres están vinculados a habilidades y características propias para la organización, cuidado, servicio y creatividad.

Palabras clave: contexto escolar, imagen de género, estereotipos.

\section{REFERENCIAS}

Lagarde, M. (1990). Identidad femenina. Recuperado de https://goo.gl/ TPqrxu

Lagarde, M. (s.f.). Identidad de género y derechos humanos. La construcción de las humanas. Recuperado de https://goo.gl/Yyc4HT

Zapata Díaz, A. (2012). Influencia de los estereotipos de género en la construcción de la identidad del niño (Tesis para optar al título de asistente social, Escuela de Trabajo Social). Academia de Humanismo Cristiano. 